\title{
Developing Intermediate EFL Learners' Metaphorical Competence through Exposure
}

\author{
Maryam Ghane Shirazi \\ Shahreza Branch, Islamic Azad University, Iran \\ Mohammad Reza Talebinezhad \\ Shahreza Branch, Iran Islamic Azad University, Iran
}

\begin{abstract}
In this article we argue that Second language learners need Metaphorical Competence (MC) which is the ability to comprehend and use metaphors in natural communication. The lack of knowledge of metaphorical concepts often leads learners to get off on a wrong foot. Learning idiomatic expressions helps learners for better communication as well as language learning in the target culture and society. This paper reports on a study done to inspect the development of conceptual fluency and metaphorical competence in Persian students of English. A group of intermediate language students were selected to be examined for the usefulness of idiomatic expressions' instruction. At the end of the instruction it was revealed that it is possible to improve learners' conceptual fluency $(\mathrm{CF})$ by the extended exposure to idiomatic expressions.
\end{abstract}

Index Terms - metaphorical competence, conceptual fluency, second language learners, idiomatic expressions

\section{INTRODUCTION}

It is obvious that language plays the lead role in communication all over the world. However, the effectivity of communication depends directly on the common understanding of both the speaker and listener who try to convey their meaning. It is noticeable that language and culture are inseparable, and they both stand in the social context. Thus, bringing the culture elements in teaching becomes more and more important. Having enough knowledge about the second language's culture, the L2 learner can comprehend that language precisely.

Among all the elements of language concerning culture, idioms are worth taking into account. Idioms are used very often in everyday communication, and fulfill the most important parts of typical conversations. Due to the difficulties of such idioms to learn and comprehend as a result of their confusing nature, English teachers must be aware of teaching the language culture as well as knowledge about that language.

Idiom is the epitome of prefab structure. Idioms are not well-defined, so literature makes attempts to define this term and find a cohesive terminology. To name some of the labels, Gloser (1984) uses the term phraseological unit, Moon (1997) chose the term multi-word items, Carter (1998) picks up the term fixed expressions, Howarth (1998) uses the term phraseology, while McCarthy(1998) prefers the traditional term idiom.

The introduction to the Oxford Dictionary of Current Idiomatic English states:'Familiarity with a wide range of idiomatic expressions and the ability touse them appropriately in context are among the distinguishing marks of anativelike command of English'.

From a psychological point of view, metaphors and idioms highlight the concept of semantic creativity, and it shows the capacity of speaker to understand and create word combinations which may be nonsense literally. Thus the comprehension of metaphor is a cognitive process. As a result, cognitive linguistics study language from the perspective of human cognition based upon cognitive science and cognitive psychology, and it attempts to investigate mechanisms in the process of comprehension and communication.

Idioms, indeed, constitute a difficult area of foreign language learning and teaching, because by definition an idiom is a group of words in a fixed order that have a particular meaning that is different from the meanings of each word understood on its own(Cambridge Dictionary). For example "to have bitten off more than you can chew" is an idiom that means you have tried to do something which is too difficult for you.

This paper attempts to provide a strategy for the teaching and learning of idioms inthe EFL classroom. Adopting a cognitive approach, idioms are seen as being motivated by underlying conceptual metaphors which are explained through a list of prepared requested expressions. The aim is to provide students with the suitable examples and situations to makesense of apparently incongruous expressions, that is, to build up their metaphoric competence, while making the learning experience enjoyable.

\section{REVIEW OF LITERATURE}

A number of studies carried out in the 1990s (e.g., Cronk and Schweigert 1992; Colombo 1993; Botelho da Silva and Cultler 1993; McGlone, Glcksberg, and Cacciari 1994) focused on idiom comprehension. Some of them such as Cronk 
and Schweigert recognized acquaintance and literalness as measurable evidence for the computation and representation of idiomatic meaning in the mental lexicon; besides, other scholars (e.g., McGlone et al. 1994) were interested in the truth of ambiguous nature and the relationship between context and different types of idioms. On the other hand the role of abstruse nature of idiom processing was the main interest of others (Botelho da Silva and Cultler, 1993).

Generally, idioms are mostly recognized as an albatross in the achievement of a foreign language, due to its arbitrary, language-specific nature. However, the practicality of phraseological language to achieve a high level of communicative competence is revealed (Lattey 1986, Nattinger and Decarrico 1992, Howarth 1998, Littlemore and Low 2006). Littlemore and Low (2006) proved the fact that metaphoric competence has important role in conveying all aspects of communicative competence (grammatical, textual, illocutionary, sociolinguistic, and strategic competence).

Talking about idiomatic expressions, we have to pay attention to all aspects of its surroundings, such as metaphorical competence, conceptual metaphors, followed by conceptual fluency. In fact, cross-linguistic studies have shown that a wide range of idioms and conceptual metaphors have a universal root, indicating that the common source of metaphoric production is grounded in our sensorimotor experiences and our interaction with the physical world (GG. Lakoff and M. Johnson 1980, 1999, M.Johnson 1987, R.Gibbs, 2003).

\section{Metaphorical Competence and Conceptual Fluency}

Since 1985, the term metaphor has been used to refer to the all figurative language and the other aspects are considered as particular kinds of metaphor (Danesi 2003).

A subject matter in the study of SLA in recent years is the extent to which learners of an L2 learn how to express themselves in the target language using figurative speech going with the culture. Danesi $(1986,1992)$ has called this a neglected dimension in L2 teaching. Gibbs (1994), in investigating the psycholinguistic cases on figurative language, explains that in proper contexts people mostly use the metaphorical asset of a message rather than its literal meaning. Therefore, metaphors are feature of communicative interaction (cited in Lantolf \& Thorne 2006, p.113). Danesi (1994) has made the term "Conceptual Fluency" to describe the ability of speaker to tap effectively into the cultural and linguistic reservoir of verbal images. So, being conceptually fluent in a language means to know how that language contemplates or illustrates its concepts based on the metaphorical structuring.

\section{Language Learning and Conceptual System}

Beck (1982) noticed that the conceptual system described by Lakoff and Johnson has possible applications in education, mainly in language study and cultural comprehending. Besides, Danesi (1986, 1989, 1992, 1994, 1995, 2003) has applied this view of language and thought to the field of SLT and SLA. He asserts that to learn a language entirely, we must have the ability to apply and encode the expressions in accordance with the conceptual system in which the language is originated. This ignored aspect of L2 pedagogy is what Danesi (1992) calls "Metaphorical Competence": the ability to comprehend and use metaphors in a language as used in natural discourse; that is, L2 learners are conceptually fluent when they have reached to native-like MC.

He argues that teaching has no taught this ability to L2 learners. Conceptual Fluency Theory suggests that underlying any given linguistic system is a conceptual system which operates as the source not only for language, but also for cognitive functioning in general: it is in terms of our conceptual system that we speak, think, perceive, and interpret the word. Therefore, to acquire another language, L2 learners ought to express themselves in the TL while applying the L2 conceptual system in a truly native-like situation. In order to be conceptually fluent is to be able to participate and interact with a target culture perception, and comprehend like a native.

\section{Why are idioms used?}

Idioms are generally a part of language, and it is not right to restrict it to just English. To express the meaning, idioms are more vivid, and of course more brief, comparing to the literal explanation. For example, it is told that an idiom gives all information which is needed but condenses it by giving a mental image that explains everything, so idioms give the meaning 'in a nutshell'. Idioms highly enrich the English language, and although it is possible to communicate correctly in non-idiomatic English, a student with only a superficial knowledge of English idioms will find him/herself at a serious disadvantage in his/her reading comprehension, and even more so while taking part in discussions and debates.

\section{How do you learn idioms?}

To learn numerous idioms, going through the English authentic texts or listening to native speakers will come in useful. After a while some idioms will become known, and the appropriate context to use will be learned. What is important to know in this case is to learn them contextually.

\section{Why and when should we use idioms?}

Idioms are one of the main categories of a language. So to communicate with foreign language speakers, we have to know the idioms. But we should use them when we're sure that we're using them correctly; we may use an idiom that is not right for the situation, and it sounds rather strange, it may mean something different to our intended use.

\section{STATEMENT OF THE PROBLEM}

In learning a language, vocabulary knowledge has an essential role in understanding and using that language. Besides, expressions convey literal or nonliteral meaning, but imply deeper meanings hidden under the surface meanings. These metaphorical meanings are mostly hard for foreign language learners to understand and use. 


\section{METHODOLOGY}

\section{Participants}

A group of 20 Persian-speaker, adult learners of English as a foreign language at the intermediate level were homogenized in terms of their English proficiency through astandard test of OPT, which was administered a month before the study. Participants were told that the results of the study are for educational purposes and were asked to write their names so that they would take the tasks seriously. Participants were both male and female whose ages ranged from 18 to 28 . Even though the students were studying in the same level entitled by the institute, to confirm the homogeneity of each member of a group and to determine the proficiency level, an OPT (Oxford Placement Test) had been administered before the study was carried out.

\section{Materials}

After conducting a survey to find out what students like to discuss, they were asked to write the expressions they really liked to know in English for each topic. The aim behind this way of collecting the idioms was to ensure the interest of students. Then a list of most common and practical expressions requested by them, were prepared by the use of Cambridge Dictionary and English Idiom Organizers.

\section{Procedure}

The procedure has three steps in four different topics:

Step 1: having adiscussion on the topic (pre-test);

Step2: Instruction of the prepared list of expressions;

Step 3: having another discussion on the same topic.

As the first step of the procedure, the students were asked to discuss the first topic. Their voices were recorded at the time, to be transcribed later. From the next session, the process of teaching the list of idioms on that topic started. Sixteen idioms in each list were taught in four sessions-each session 4 expressions. The process of teaching the idioms was completely controlled.First of all; the idioms' meaning was explained for the students by using suitable contexts. In this way students understood the use and usage of those idiomatic expressions. What was really important for me to teach was to instruct the students how to use the expressions structurally. With respect to the fact that the goal wasto get students to not only understand idioms, but also learn how to use them effectively, the students faced with the appropriate examples for each expression, and then they were asked to give good examples themselves. Then, they were grouped in pairs to work together on the expressions. Each group was asked to be ready for role playinga conversation, the session after the instruction of that part. After presenting the students-made-conversation by the pairs, their classmates had to givea report about what they said, by the use of the expressions. After finishing the instruction sessions, in the fifth session, the students were asked to have another discussion on the same topic, and again their voices were recorded.The protocol for the other topics continued until the last session of the semester, to cover the entire topics.

\section{RESULTS AND DISCUSSION}

Students' voices were recorded to be transcribed to find out the difference between the density of using expressions in the discussions before and after the instruction. Before having adiscussion on the results, it should be mentioned that in order to prevent the test effect, the specific time interval between the pre-test and post test, and also between the instruction period and the post-test were controlled.

The data showed that the density of expressions in the post test was higher than the one in pre-test, and it shows that the treatment was successful. However what was really interesting was the difference between using the expressions, by students, during the instruction and in the post-test. Although the students' voices were not recorded while practicing in the class during the four sessions of instruction, the researcher noticed they used the expressions more, in their own conversations and while reporting the others' conversations. As a result, they were expected to have higher density of expressions in the post-test. Having fewer expressions in post-test comparing to the practices in the classroom, can refer back to the variety of reasons, which can be a subject for further researches.

Watching the recorded pre-test revealed that the ability of students for using the expressions, except two of them who used more expressions, was somehow the same. They mostly used the routine cliché expressions, which are practical in every day conversation, and they face them regularly in previous semesters, such as of course, as a matter of fact, etc.

In the statistics analysis, descriptive statistics were used to gain primary information such as mean, the maximum and minimum amount, and the standard deviation.

The following table indicates the descriptive statistics for the 8 scores for the 4 topics, all of which wereextracted based on the data from 20 participants. In pre-tests the minimum score is 0 , while in the post-tests the minimum score has raised up to 2. Concerning the maximum, we see that the scores 3 (pre-test T1), and 2 (pre-test T2,3,4) have increased up to 9 and 8 correspondingly. The mean for the pre-tests are $0.55,0.75,0.8$ and 0.8 , which are drastically grown to $6.25,5.35,5.2$ and 6 , in order. 
TABLE 1.

DESCRIPTIVE STATISTICS

\begin{tabular}{|c|c|c|c|c|c|}
\hline & $\mathrm{N}$ & Minimum & Maximum & Mean & Std. Deviation \\
\hline Prt test T1 & 20 & .00 & 3.00 & .5500 & .88704 \\
\hline Prt test T2 & 20 & .00 & 2.00 & .7500 & .85070 \\
\hline Prt test T3 & 20 & .00 & 2.00 & .8000 & .76777 \\
\hline Prt test T4 & 20 & .00 & 2.00 & .8000 & .69585 \\
\hline Post testT1 & 20 & 2.00 & 9.00 & 6.2500 & 2.02290 \\
\hline Post testT2 & 20 & 2.00 & 8.00 & 5.3500 & 1.59852 \\
\hline Post testT3 & 20 & 2.00 & 8.00 & 5.2000 & 2.06729 \\
\hline Pos test tT4 & 20 & 2.00 & 8.00 & 6.0000 & 1.48678 \\
\hline
\end{tabular}

For the inferential statistics Kolongraph-Smirnov test were used for obtaining normal and non-normal variables.Based on Kolmogrov-test, the hypothetical zero shows the normal variables, otherwise the variables will be non-normal. The statistic degree of the test is based on $\mathrm{Z}$ statistic, and for proving or rejecting the hypothesis we use the significance level, P-value. If the significance level is less than 0.05 ( $\alpha<0.05$ ), the variable will be non-normal, while the significance level of above 0.05 ( $\alpha>0.05$ ) shows the normal variables. Based on the result of KolomogrovSmirnov test, as the table shows in the appendices, variables T1 and T2 are non-normal, for which we use Wilcoxon test; and variables T3 and T4 are normal variables, for which we use T-test.

T1:

The table for comparing pre-test and post-test of $\mathrm{T} 1$ shows that the results for all the participants in post-test is more than the pre-test, and none of the participants has the same result in pre-test and post-test(Ties). The statistic level is 3.954 with the significance level of 0.000 , which is less than 0.5 . so the hypothesis of the equality of pre-test and posttest is rejected. Now the goal is to understand whether the instruction is helpful. The amount of post-test minus pre-test is equal to 20; that is, in all of them the density of using expressions in post-test are more than pre-test. So the instruction was helpful in T1.

TABLE2.

WILCOXON SIGNED RANKS TEST FOR T1

\begin{tabular}{|c|c|c|c|}
\hline & & $\mathrm{N}$ & Mean Rank \\
\hline \multirow{4}{*}{ PostT1 - PrtT1 } & Negative Ranks & $0^{\mathrm{a}}$ & .00 \\
\hline & Positive Ranks & $20^{\mathrm{b}}$ & 10.50 \\
\hline & Ties & $0^{\mathrm{c}}$ & \\
\hline & Total & 20 & \\
\hline $\mathrm{Z}$ & & -3.954 & \\
\hline Asymp. Sig. (2-tailed) & & .000 & \\
\hline & $\begin{array}{l}\text { a. Pos } \\
\text { b. Pos } \\
\text { c. Pos }\end{array}$ & & \\
\hline
\end{tabular}

T2:

The result will be the same for T2, with the difference in statistic level, which is -3.943 for T2, with significance level of 0.000 .

TABLE3.

Wilcoxon Signed Ranks Test for T2

\begin{tabular}{|c|c|c|c|}
\hline & & $\mathrm{N}$ & Mean Rank \\
\hline \multirow[t]{4}{*}{ PostT2 - PrtT2 } & Negative Ranks & $0^{\mathrm{a}}$ & .00 \\
\hline & Positive Ranks & $20^{\mathrm{b}}$ & 10.50 \\
\hline & Ties & $0^{c}$ & \\
\hline & Total & 20 & \\
\hline $\mathrm{Z}$ & & -3.943 & \\
\hline Asymp. Sig. (2-tailed) & & .000 & \\
\hline & $\begin{array}{l}\text { a. I } \\
\text { b. I } \\
\text { c. I }\end{array}$ & $\begin{array}{l}\mathrm{rtT2} \\
\mathrm{rtT2} \\
\mathrm{rtT2}\end{array}$ & \\
\hline
\end{tabular}

Thus, in all 20 cases the expression density of participants' post-test were more than pre-test, and it shows that the instruction in $\mathrm{T} 2$ were effective, too. 
T3:

As it was written before, we use T-test for the normal variables T3 and T4.

The level of statistic for T3, based on T-test is equal to 10.655 , and the level of significance is 0.000 , which is less than 0.05; so the hypothetical zero, to show the equality of pre-test and post-test, is rejected. The difference of means is 4.4, which is a significant difference, and it demonstrates the superiority of post-test over pre-test. Therefore the T3's instruction was meaningful and helpful.

TABLE4.

T-TEST FOR T3

\begin{tabular}{|l||l|l||l|l|l|}
\hline \multicolumn{1}{|c||}{} & \multicolumn{3}{c|}{} & & \\
\cline { 2 - 6 } & & & & & \\
& Mean & Std. Deviation & t & Df & Sig. (2-tailed) \\
\hline \hline PostT3 - PrtT3 & 4.40000 & 1.84676 & 10.655 & 19 & .000 \\
\hline
\end{tabular}

T4:

The same process was done for T4. The statistic level is 14.166, and the significance level is 0.000 . Besides the difference between the means in pre-test and post-test is 5.2. it demonstrates that the post-test mean is 5.2 units more than pre-test's. therefore the T4's instruction was useful and effective.

TABLE4.

T-TEST FOR T3

\begin{tabular}{|c|c|c|c|c|c|}
\hline & Mean & Std. Deviation & $\mathrm{T}$ & Df & Sig. (2-tailed) \\
\hline PostT4 - PrtT4 & 5.20000 & 1.64157 & 14.166 & 19 & .000 \\
\hline
\end{tabular}

Generally the instructions for all the 4 topics were meaningful. The following chart shows the mean in all the 4 variables, and demonstrates that the mean in all 4 topics have noteworthy achievement.

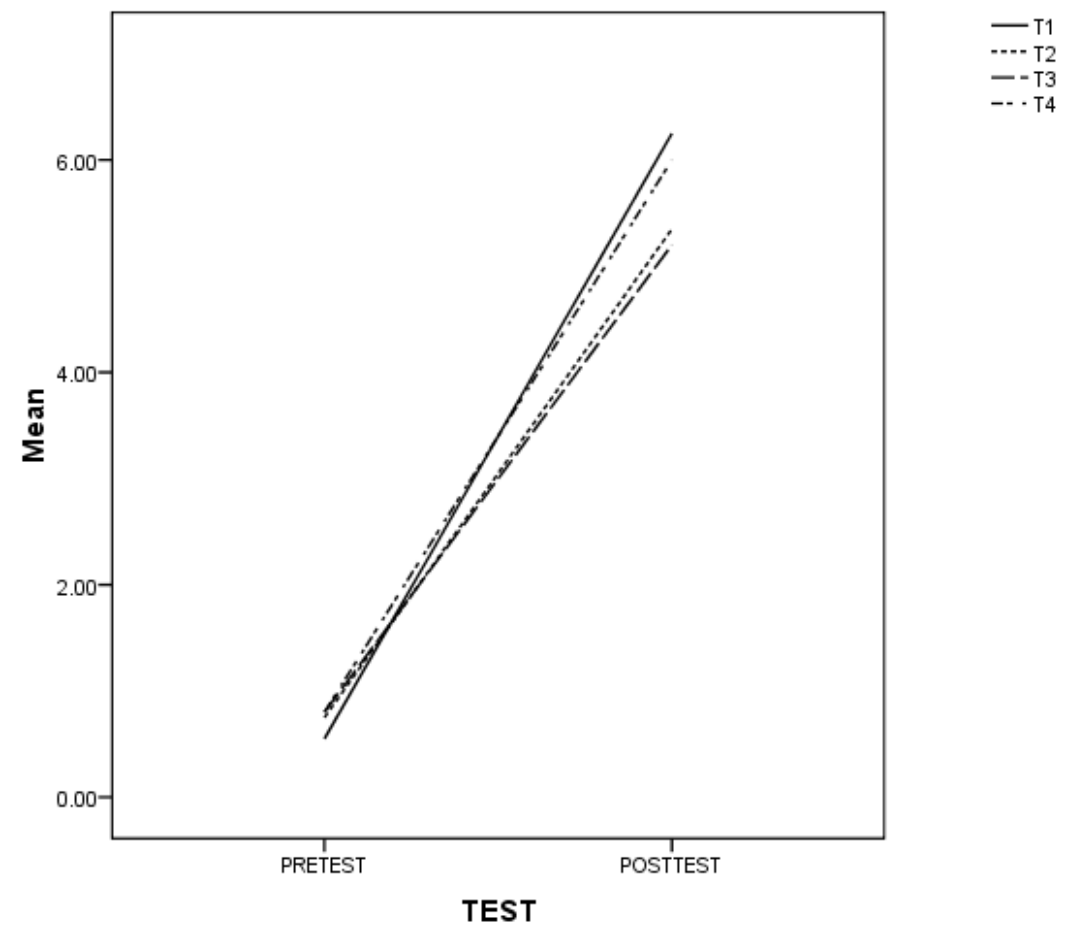

Checking the papers carefully, we come to the conclusion that they can use the mostly-used expressions in a correct way; That is, they know how to use them structurally, and also use them in an appropriate situation, which was the result of practicing for a long time during the past semesters.

\section{CONCLUSION}


The importance of knowing figurative language while speaking as the native-speaker or non-native speaker, is now attested to by most researchers in the field. We know that figurative occur less frequently than many phrasal verbs, collocations and discourse markers so may deserve less teaching time. However, as Liu (2003) has mentioned, even low frequency figurative could be important occasionally so teaching students the skills to comprehend the figurative when it occurs in discourse will help them become more independent and conceptual fluent learners. On the other hand, lack of idiom knowledge will have an effect on the learners' overall performance. Hence, it is essential for both instructors and learners to deal with idioms in a well defined situations and contexts, where topics such as idiom definition or teaching methodology are solved. This is the only way the educational process as a whole will be advantageous for the participants.

It is noticeable that fluent non-native speakers, even highly competent speakers of English, significantly cannot perform as well as native speakers in understanding and comprehending idiomatic versus literal meanings of vague sentences in different situations. Many idioms can have several meanings depending on the context within which they are used.

Idioms can be difficult even for native speakers, and therefore, one cannot expect second language learners to know the meanings of idioms outside context or to produce them in their own speech or writing. So as these findings indicate, context plays an important role in the construction of idiomatic meaning; Thus having contextualized idioms in the syllabus can be really useful for improving learners metaphorical competence, therefore to make them conceptual fluent. Besides, what was extremely beneficial for students to learn and use the expressions was the multi-exercise which are used as the practicing of the idioms. After all, idioms are an essential part of language and they should not be ignored in language teaching even though they tend to be difficult for learners.

In general more idiom studies concentrating on second or foreign language learners should be conducted in order to learn more about the language learning process. It is difficult to say how much the given brief context and the tasks affected comprehension. Further research is needed to examine more carefully their impact. Moreover, further study is needed to examine more the effects of the students' background and involvement with the language on idiom comprehension.

APPENDIX

\begin{tabular}{|c||c|c|c|c|c|c|c|c||c|c|}
\cline { 2 - 10 } \multicolumn{1}{c|}{} & \multicolumn{9}{|c|}{ Pre-test } & \multicolumn{5}{|c||}{ Post-test } & \multicolumn{1}{|c|}{} \\
\hline T1 & T2 & T3 & T4 & T1 & T2 & T3 & T4 & A1 & A2 \\
\hline S1 & 0 & 2 & 0 & 1 & 6 & 5 & 6 & 7 & 3 & 24 \\
\hline S2 & 0 & 0 & 1 & 2 & 5 & 6 & 6 & 6 & 3 & 23 \\
\hline S3 & 0 & 1 & 1 & 0 & 5 & 6 & 4 & 6 & 2 & 21 \\
\hline S4 & 1 & 0 & 1 & 1 & 8 & 4 & 7 & 7 & 3 & 26 \\
\hline S5 & 0 & 1 & 0 & 1 & 3 & 2 & 2 & 5 & 2 & 12 \\
\hline S6 & 1 & 1 & 0 & 1 & 3 & 5 & 2 & 5 & 3 & 15 \\
\hline S7 & 0 & 0 & 1 & 0 & 7 & 4 & 8 & 7 & 1 & 26 \\
\hline S8 & 0 & 0 & 0 & 1 & 8 & 7 & 7 & 8 & 1 & 30 \\
\hline S9 & 0 & 1 & 0 & 0 & 7 & 6 & 4 & 6 & 1 & 23 \\
\hline S10 & 2 & 0 & 2 & 1 & 8 & 6 & 4 & 7 & 5 & 25 \\
\hline S11 & 0 & 0 & 2 & 0 & 7 & 5 & 7 & 8 & 2 & 27 \\
\hline S12 & 0 & 2 & 1 & 1 & 7 & 7 & 5 & 7 & 4 & 26 \\
\hline S13 & 2 & 2 & 1 & 2 & 9 & 8 & 6 & 4 & 7 & 27 \\
\hline S14 & 1 & 0 & 0 & 1 & 4 & 6 & 4 & 6 & 2 & 20 \\
\hline S15 & 0 & 1 & 0 & 0 & 2 & 3 & 2 & 2 & 1 & 9 \\
\hline S16 & 0 & 2 & 1 & 1 & 8 & 8 & 7 & 7 & 4 & 30 \\
\hline S17 & 3 & 2 & 2 & 2 & 8 & 6 & 4 & 6 & 9 & 24 \\
\hline S18 & 0 & 0 & 2 & 1 & 7 & 5 & 8 & 5 & 3 & 25 \\
\hline S19 & 1 & 0 & 1 & 0 & 8 & 5 & 8 & 7 & 2 & 28 \\
\hline S20 & 0 & 0 & 0 & 0 & 5 & 3 & 3 & 4 & 0 & 15 \\
\hline
\end{tabular}

A: Average score

ONE-SAMPLE KOLMOGOROV-SMIRNOV TEST

\begin{tabular}{|c|c|c|c|c|c|c|c|c|}
\hline & ||PrtT1 & PrtT2 & PrtT3 & PrtT4 & PostT1 & PostT2 & PostT3 & PostT4 \\
\hline Kolmogorov-Smirnov Z & 1.710 & 1.391 & 1.124 & 1.177 & 1.094 & .730 & .757 & .894 \\
\hline Sig. (2-tailed) & .006 & .042 & .160 & .125 & .183 & .660 & .616 & .400 \\
\hline
\end{tabular}




\section{REFERENCES}

[1] Danesi, M. (2003). Second language teaching: A view from the right side of the brain. The Netherlands: Kluwer Academic Publishers.

[2] Ellis, R. (1994). The study of second language acquisition .Oxford: Oxford University Press.

[3] Fernando, C. (1996). Idioms and idiomaticity. Oxford: Oxford University Press.

[4] GIBBS, R. W., (2003). Embodied experience and linguistic meaning. Brain and Language, 84, 1-15.

[5] Gläser, R. (1984). The translation aspect of phraseological units in English and German. Papers and Studies in Contrastive Linguistics, 18, 123-134.

[6] Golshan, M. (2009). A dictionary of the origins and stories of English idioms. Tehran, Iran: Jungle Publication.

[7] Howarth, P. (1998). Phraseology and second language proficiency. Applied Linguistics, 19(1), $24-44$.

[8] Johnson, M. (1987). The Body in the Mind. Chicago: The University of Chicago Press.

[9] Ketabi, S., \& Shomoosi, N. (2007). Native speaker and teaching English as an international language. Iranian Journal of Language Studies (IJLS), 1(3), 171-180.

[10] Lakoff, G., \& Johnson, M. (1980). Metaphors we live by. Chicago: University of Chicago Press.

[11] Littlemore, J., \& Low, G. (2006). Metaphoric competence, second language learning, and communicative language ability. Applied Linguistics, 27(2), 268-294.

[12] Liu, D. (2003). The most frequently used spoken American English idioms: A corpus analysis and its implications. TESOL Quarterly, 38(4), 671-700.

[13] McCarthy, M. (Ed.). Vocabulary, description, acquisition and pedagogy (pp.40-63). Cambridge: Cambridge University Press.

[14] McCarthy, M. J. (1998). Spoken language and applied linguistics. Cambridge: Cambridge University Press.

[15] McCarthy, M., \& Carter, R. (1994). Language as discourse: Perspectives for language teaching. London: Longman.

[16] McCarthy, M., \& O’Dell, F. (2002). English idioms in use. Cambridge: Cambridge University Press.

[17] Nattinger, J. R., \& DeCarrico, J.S. (1992). Lexical phrases and language teaching. Oxford: Oxford University Press.

[18] Oxford Idioms Dictionary for learners of English. (2001). Oxford: Oxford University Press.

[19] Schmidt, Ch. M. (2007). Metaphor and Cognition: A cross-cultural study of indigenous and universal constructs in stock exchange reports. Retrieved March 15, 2008 from, http://immi.se/intercultural/nr5/schmidt.doc

[20] Talebinejad, M.R., \& VahidDastjerdi, H. (2005). A cross-cultural study of animal metaphors: When owls are not wise. Metaphor and Symbol, 20(2), 133-149.

Maryam Ghane Shirazi was born in Shiraz, Iran, in 1985. She got her B.A. in English Language and Literature from Science \& Culture University, Isfahan Branch, Iran. She continued her university studies in TEFL for an M.A. degree, and got her M.A. degree from Shahreza Azad University, Isfahan, Iran in 2012.

She has been an English teacher in different levels, up to advanced, since 2006, and also she's worked as an Educational Counselor and Expert in Jahad Daneshgahi (IUT branch), Isfahan, Iran.

Mohammad Reza Talebinezhad is an Associate Professor of Applied Linguistics at Islamic Azad University, Shahreza Branch. $\mathrm{He}$ is also an associate faculty member at Sheikhbahaee University, Iran.

Dr Talebinejad received his BA in English Language and Literature, University of Isfahan in 1975. He then got his MA in TEFL from the University of Texas at Austin, USA in 1977. For his doctoral degree, Dr Talebinejad was admitted to the University of Sheffield, UK, where he did his PhD in Applied Linguistics in 1994.

He has widely published in Iranian as well as International professional journals such as Metaphor and Symbol, English Teaching Forum, Language Testing, IJAl, Language and Translation, Journal of Social Sciences, The International Journal of Humanities, and other local and international journals. Dr. Talebinezhad has presented papers in International conferences such as AILA, 2000; Atiner, 2011; RAAM, 2002, 2001 in Paris and Tunis, EUROSLA, Switzerland, 2006; Multicultural Conference, 2007, China. In addition, Dr. Talebinezhad has authored/coauthored eight books in related fields and ESP. 